\title{
An examination of strategy disclosure in the annual reports of South African listed companies
}

\author{
N. Padia and Y. Yasseen \\ School of Accountancy, Faculty of Commerce, Law and Management, \\ University of the Witwatersrand, Johannesburg, Republic of South Africa \\ Nirupa.Padia@wits.ac.za
}

Received August 2010

\begin{abstract}
This study examines the extent of strategy disclosure in the Annual Reports of South Africa's top one hundred companies listed on the Johannesburg Securities Exchange (JSE). Disclosure of strategy is voluntary and not required by law. Investigation into the strategy disclosure was carried out by scoring the amount of disclosure companies reported in their Annual Reports. Variables included items such as mission, goals and objectives. Two additional criteria, Human Immunodefiency Virus (HIV) / Acquired Immune Deficiency Syndrome (AIDS) and Black Economic Empowerment (BEE), were included specifically for the South African context.
\end{abstract}

Results showed that maximum disclosure per criteria was low. Overall the scores of the variables indicate that although South African companies generally do disclose a lot more information on their strategy, only six per cent of companies made maximum disclosure on all twelve criteria. The lowest scores were obtained for HIV/AIDS and BEE. The low disclosure overall has implications for users of annual reports.

*To whom all correspondence should be addressed.

\section{Introduction}

Annual reports are instruments used primarily to disclose financial, and increasingly non -financial achievements of companies to stakeholders. Although most business research focuses solely on the financial portion of the annual report, the narrative textual materials are equally important as they provide very useful information about companies (Yuthas, Rogers \& Dillard, 2002: 141). The extent of strategy disclosure, which forms part of the non- financial information in the Annual Reports, is valuable to stakeholders in assessing the potential of a company.

The research question for this study was "to what extent do South African companies disclose their strategies in their Annual Reports?"

Kohut and Segars (1992:18) noted that Annual Reports have become an increasingly popular medium for communicating corporate strategy, and it is this communication of corporate strategy which allows the firm to distinguish itself from its competitors. Annual Reports reveal a great deal more about corporate strategy than most managers realise (Bowman, 1978: 64). Mission, goals and objectives are just some of the key items that should be present in the description of a company's strategy (Santema, Hoekert, Van de Rijt \& Van Oijen, 2005: 352). Some organizations choose to share a lot of relevant information about their goals, objectives and missions while others are very reluctant to share this information (Santema, et al., 2005: 354). Kohut and Segars
(1992: 8) found that the narrative section within Annual Reports is the most influential part of the Report.

Much of the information provided by firms in their Annual Reports is not required by laws and specific regulations. AlRazeen and Karbhari, (2004: 352) distinguish between the voluntary disclosures that are closely related to the mandatory ones. Voluntary disclosures add to the quality of the Annual Reports. There has however been very little focus on the qualitative aspects of Annual Reports. While most academic research focuses on the cost benefits of financial information disclosure, a growing body of research notes the voluntary disclosure by corporations.

For the purposes of this research a quantitative research methodology was used. The research sample was made up of one hundred companies listed on the JSE which were selected from the Financial Mail's list of the top two hundred companies based on turnover (Financial Mail, 2005). Data on strategy disclosure was collected and analysed on twelve variables selected.

This paper will expand on the current research specifically in the South African Context.

\section{Literature review}

Santema et al. (2005:35) provide the following definition for "strategy disclosure": 
"The revelation of information an organisation decides to share with its stakeholders on the strategy it is pursuing and going to pursue in the future".

Previous literature has emphasised that multiple stakeholders read the same Annual Reports, each for their own strategic reason (Scholes \& Clutterbuck, 1998 as cited in Santema \& Van de Rijt, 2001: 101). Users of Financial statements include financial analysts, investors, lenders, suppliers and employees. Each of these stakeholder groups values different items in an Annual Report and the way corporations disclose their strategies in Annual Reports positively influences the quality of the Annual Report (Santema \& Van de Rijt, 2001: 101).

Most previous work has focused on financial disclosure rather than corporate strategy disclosure (Ferreira \& Rezende, 2007:166). Yuthas et al. (2002:142) state that despite their economic importance, the texts in Annual Reports have received little attention from scholars interested in the communicative effectiveness of public disclosure.

The Jenkins Committee Report published in 1994 (Flostrand \& Strom, 2006: 581-582), contained recommendations on business reporting and suggest that to meet the needs of users, business reports must:

a) Provide more information with a forward-looking perspective, including management's plans, opportunities, risks, and measurement uncertainties.

b) Focus more on the factors that create longer term value, including non-financial measures indicating how key processes are performing.

c) Better align information reported externally with the information reported to senior management to manage the business (Flostrand \& Strom, 2006: 581-582).

In essence, the users of Annual Reports were no longer thought to be satisfied with conventional Annual Reports including balance sheets, income statements, cash-flow statements, and statements of changes in owners' equity. According to the Jenkins Committee (Flostrand \& Strom 2006:591), Annual Reports now had to include information relevant in predicting the future performance of the firm, whatever form or shape that information might have. Users were looking for leading, instead of lagging, indicators of performance; rather than being told what last year's return on investment was, users wanted information that would help them forecast future returns on investment. Investors started requesting information they could use, that is, information that was valuation relevant. Therefore a business's strategy is very important (Flostrand \& Strom, 2006: 582). Flostrand and Strom (2006:591) found that information needs of users of financial statements are changing from quantitative to qualitative and financial to non- financial.

In a study conducted in Denmark, Bukh, Nielson, Gormsen and Mouritsen (2005:715) found that non-financial information has lower priority than traditional financial information. There are benefits to capital markets from companies voluntary disclosing information. Increased disclosure reduces the cost of capital, increases liquidity and increases information intermediation (Vanstraelen, Zarzeski \& Robb, 2003:249).

Santema and Van de Rijt, (2001:102) investigated the extent to which Dutch Firms disclose their strategy in the Annual Report using a set of ten criteria (Table 1). Their focus was to analyse the narrative aspects of Annual Reports (Santema \& Van de Ritj, 2001:102). The main finding of their study was that Dutch listed firms generally do not disclose a lot of information on their corporate strategy. They also found that future oriented action plans were rarely disclosed (Santema \& Van de Ritj, 2001:107). South African companies are governed by local requirements and legislation in producing their Annual Reports.

\section{Annual reporting in South Africa}

In South Africa listed companies are governed by the Companies Act as well as the Johannesburg Securities Exchange (JSE). The objective of financial statements is to provide information about the financial position, performance and changes in financial position of an entity that is useful to a wide range of users in making economic decisions (SAICA, 2009/9b).

A complete set of financial statements comprises a statement of financial position as at the end of the period:

- a statement of comprehensive income for the period,

- a statement of changes in equity for the period,

- a statement of cash flows for the period,

- $\quad$ notes, comprising a summary of significant accounting policies and other explanatory information;

- and a statement of financial position as at the beginning of the earliest comparative period when an entity applies an accounting policy retrospectively or makes a retrospective restatement of items in its financial statements, or when it reclassifies items in its financial statements (SAICA, 2009, 1(a):20). /9a).

The Companies Act requires the companies to comply with the Act and with accounting standards (SAICA 2009/10: 198). Except for the above requirements, the disclosures made in the Annual Reports are voluntary. The disclosures required by the King III Code for Corporate Governance (IOD, 2009:11) are recommended; and the JSE requirements state that the listed companies have to disclose whether they 'apply' with the King Code or not. If not, 'explain' why and give reasons for not applying the recommended practice.

However if the King Code is not applied, this is not against the law. The King Code has distinguished between statutory provisions as opposed to practices; and made it clear that it is the board's duty, if it believes it to be in the best interests of the company, to override a recommended practice. A company will become aware from its stakeholders whether a 
departure from a recommended practice is or is not seen to be in the best interests of the company.

Good governance is essentially about effective leadership. Leaders need to rise to these challenges if there is to be any chance of effective responses. Leaders need to define strategy, provide direction and establish the ethics and values that will influence and guide practices and behavior (IOD, 2009:12) This is all inherent information in the nonfinancial sections of the Annual Report.

\section{Research methodology}

The research question this study addresses is:

To what extent do South African companies disclose their strategies in their Annual Reports?

The purpose and value of this research in a South African context is of significance because South African listed companies are regarded by foreign institutional investors as being among the best governed in the world's emerging economies (Financial Mail, 2005). Companies must have clear and focused strategies and policies in place to be competitive and sustainable. In this regard the extent of strategy disclosure in the Annual Reports of companies is an important factor.

The methodology used is quantitative. The research sample comprised one hundred companies listed on the JSE which were selected from the Financial Mail's list of the top two hundred companies based on turnover (Financial Mail, 2005).

Data was collected from the 2005 Annual Reports which were obtained from McGregor BFA's or directly from the respective company websites. The data was collected on the strategy disclosure on the twelve variables selected (Table 1) and Statistical Modelling was used to analyse the data.

This is an analytical study in which the narrative components of Annual Reports were analysed using twelve criteria. The first ten criteria were selected from the Santema and Van de Rijt, (2001:102) research into Strategy Disclosure in Dutch Annual Reports. Two additional criteria, HIV/AIDS and Black Economic Empowerment (BEE) have been added as they are of paramount importance to firms operating in a South African Context (Table 1). The HIV/AIDS variable was included, because in South Africa, approximately 5,5 million from a population of forty million people were infected with the disease ( Du Bruyn, 2008:59); and the South African workforce is therefore impacted greatly by this disease. Whilst the firms in South Africa have no legal obligation to provide care and support to those affected and infected by HIV/AIDS, the questions of skills shortage and job replacement arise coupled with corporate social responsibility. The BEE is also a significant factor due to the history of disadvantage and discrimination (or exclusion) of certain race groups in South Africa. The two criteria were therefore added to assess whether the corporate sector have actually taken steps to include the disclosure on HIV/AIDS and BEE in their Annual Reports.
Table 1: Strategy disclosure criteria

\begin{tabular}{c|l}
\hline 01 & Mission: What does the company want to be? \\
\hline 02 & Goal: What General Controls does the company have? \\
\hline 03 & $\begin{array}{l}\text { Objectives: Which concrete quantitative goals does the } \\
\text { company have? }\end{array}$ \\
\hline 04 & $\begin{array}{l}\text { Corporate Strategy: What is the Corporate Strategy that } \\
\text { the company has? }\end{array}$ \\
\hline 05 & $\begin{array}{l}\text { Consistency: Is the corporate strategy in line with the } \\
\text { statements on strategy in previous reports? }\end{array}$ \\
\hline 06 & $\begin{array}{l}\text { Monitoring: Are the goals and the objectives monitored? } \\
\text { Strategies * }\end{array}$ \\
\hline 07 & $\begin{array}{l}\text { Business Units Goals: Which goals do the Business Units } \\
\text { have? }\end{array}$ \\
\hline 08 & $\begin{array}{l}\text { Business Unit Strategies: What are the strategies of the } \\
\text { Business Units? }\end{array}$ \\
\hline 10
\end{tabular}

Adapted from Santema et al (2001:102). Criteria 11 and 12 were added due to relevance in the South African context

The Annual Report of each of the one hundred companies was individually inspected and an individual score on each item was compiled. This was then statistically analyzed using the computer program STATA version 10. Some of the analysis included was the perce score, Cronbach alpha for internal consistency and a two-dimensional biplot of the dataset. These assisted in analysing the extent of disclosure and whether there was significant correlation among the variables.

The sample of the one hundred companies was rated on the twelve variables selected. A score of zero would denote no disclosure, and a score of one would denote maximum disclosure. The companies were rated for partial disclosure with the scores from $0,25,0,5$ and 0,75 (Table 2).

The analysis of the data in respect of strategy disclosure in the Annual Reports is presented in the results.

\section{Results}

Analysis of the scores (Table 3 and Figure 1) reveals that there are a higher percentage of companies that disclose their vision, mission and goals, and very few companies that make strategy disclosure on HIV/AIDS and/or BEE policies. 
Table 2: Scoring table: Example of the criterion HIV/AIDS

\begin{tabular}{l|l}
\hline Score & \\
\hline 0 & $\begin{array}{l}\text { The company does not have an HIV/AIDS } \\
\text { Strategy }\end{array}$ \\
\hline 0.25 & $\begin{array}{l}\text { Some HIV/AIDS Strategy is in place } \\
\text { Strategy in place }\end{array}$ \\
\hline 0.5 & There is a well defined HIV/AIDS Strategy \\
\hline 1 & $\begin{array}{l}\text { There is a comprehensive HIV/AIDS Strategy } \\
\text { in place }\end{array}$ \\
\hline
\end{tabular}

Scores were allocated based on the level of HIV/AIDS strategy in place. Similarly, scores were allocated to the other 11 criteria listed in Table 1 on a consistent basis.

The results have been analysed using four distinct categories of the twelve variables. The variables have been divided according to goals, action plans, business units and the South African specific variables of HIV/AIDS and BEE.

Category 1 consists of mission, objective and goal. On average 41 per cent scored a maximum of 1 , which means full strategy disclosure, with regard to these three variables 51 per cent have made partial disclosure and only 8 per cent have made no disclosure at all. This may be due to the fact that frameworks for vision, mission and goals are

\section{Table 3: Scores for sample companies for the twelve variables}

\begin{tabular}{l|c|c|c|c|c}
\hline Category & $\mathbf{0}$ & $\mathbf{0 , 2 5}$ & $\mathbf{0 , 5}$ & $\mathbf{0 , 7 5}$ & $\mathbf{1}$ \\
\hline Mission & 11 & 12 & 21 & 14 & 42 \\
\hline Objective & 2 & 21 & 18 & 17 & 42 \\
\hline Goal & 11 & 11 & 16 & 22 & 40 \\
\hline Corporate strategy & 12 & 13 & 18 & 13 & 35 \\
\hline Actions plans ex post & 12 & 13 & 28 & 14 & 34 \\
\hline Action plans ex ante & 14 & 14 & 24 & 33 & 34 \\
\hline Consistency & 4 & 12 & 21 & 20 & 29 \\
\hline Monitoring & 12 & 13 & 26 & 20 & 28 \\
\hline Business units strategies & 12 & 12 & 25 & 20 & 26 \\
\hline Business units goals & 14 & 15 & 20 & & 12 \\
\hline BEE & 29 & 23 & 23 & 14 & 15 \\
\hline
\end{tabular}

widespread and companies know what is expected in terms of disclosure in these areas.

Category 2 consists of corporate strategy, actions ex post, and action plans ex ante. On average 34 per cent scored a maximum of 1,53 per cent have made partial disclosure and 13 per cent have made no disclosure at all. This may be attributed to the fact that companies are reluctant to disclose much about their future action plans or comment on the previous year's forecasted action plans; and whether these were achieved. This could also be due to companies not willing to make their action plans widely available to their competitors.

Category 3 consists of monitoring, business unit strategies, consistency, and business unit goals. Here the average score for full disclosure was 28 per cent. On average 61 per cent of companies have made partial disclosure and 11 per cent have made no disclosure at all. This could be as a result of companies not having much strategy in place for these variables.

Category 4 which was made up of HIV/AIDS and BEE, had the lowest score of maximum disclosure with 16 per cent for HIV/AIDS and 15 per cent for BEE. Partial disclosure on average was made by 59 per cent of companies. 29 per cent of companies had a score of zero for HIV/AIDS and 23 pe rcent for BEE which means they made no disclosure at all for these variables. This may be due to the fact that very little structure or guidelines for HIV/AIDS and BEE disclosure; as these are relatively new variables and South African specific. 


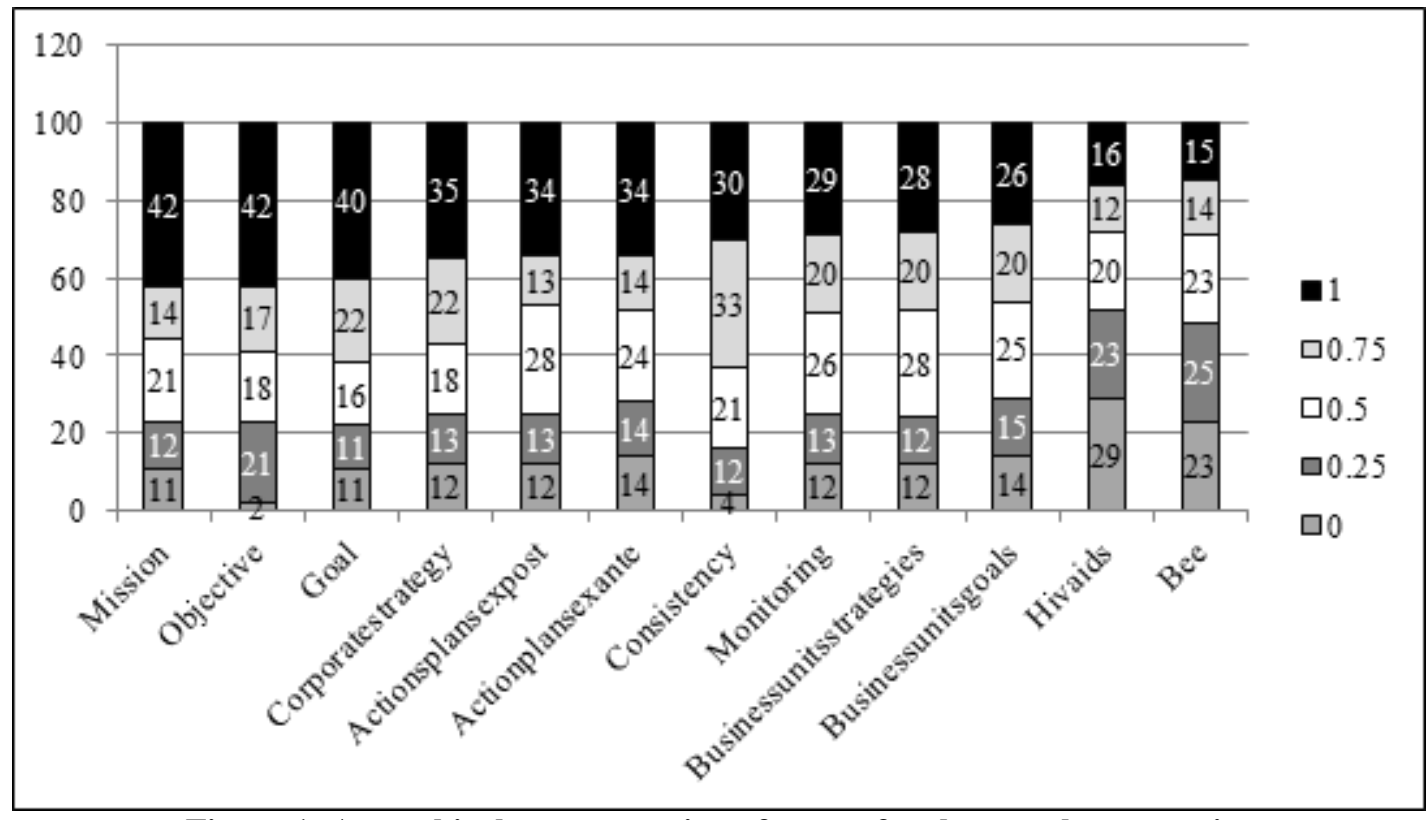

Figure 1: A graphical representation of scores for the sample companies

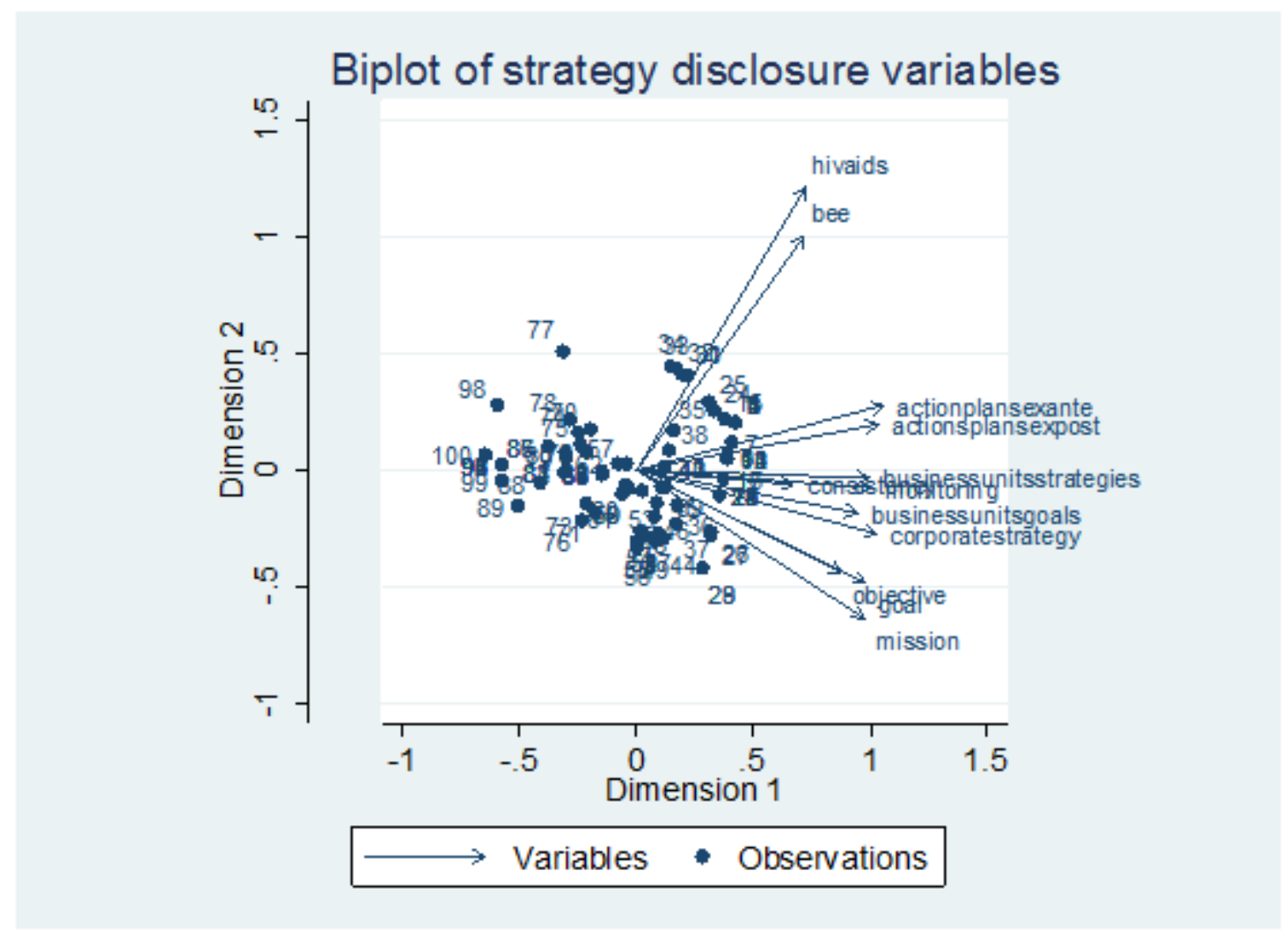

Figure 2: Biplot of strategy disclosure

The biplot reveals the connectivity among these various categories. The angle between the objective and goal on the biplot is very small. These two variables appear as if they almost overlap. Mission is also very close to goal and objectives. This implies that they are almost perfectly correlated. The company that makes disclosure on objective will be inclined to provide disclosure on goal and mission as well and vice versa. The correlation among these three variables in category one is therefore high.

However, in category two, corporate strategy was at 35 per cent (Fig 1), but on the biplot (Fig 2) it is more closely linked to the business unit goals of category three. The seven variables of categories two and three are also closely linked on the biplot. There is partial disclosure in these variables.

The HIV/AIDS and BEE variables are situated quite a distance away from the other variables. This is in line with category four which had minimum disclosure.

The per cent score analysis was performed for all of the variables; and the $\mathrm{p}$ value was less than 0,0001 which revealed statistical significance (Table 4). As can be observed from Table 3, although the HIV/AIDS and BEE may have lower scores than the rest, these also have $p$ 
values that are below 0,0001. This is a good indication. None of the $\mathrm{p}$ values were above 0.05 to indicate that there is no statistical significance.

Further analysis was performed using the Cronbach Alpha for internal consistency (Table 5). This was done on all the variables. A score of over 70 per cent is a strong indication that there is internal consistency among these variables. Each of the individual alpha scores was greater than 90 per cent. The total was 97, 17 per cent indicating an extremely high correlation among the variables.
As the variables selected were based on the previous study (Santema \& Van de Ritj, 2001:102) and HIV/AIDS and BEE were added for a South African context, it is expected that these items should have very good internal consistency. The trend that would be expected is that companies that do disclose their strategy would make disclosure on most of these variables to a greater or lesser extent. However, the companies that do not make strategy disclosure would naturally make minimal disclosure on most of these variables.

Table 4: Per cent statistical analysis

\begin{tabular}{|c|c|c|c|c|c|c|c|}
\hline perce_score & 1,0000 & & & & & & \\
\hline \multirow[t]{2}{*}{ Mission } & 0,8852 & 1,0000 & & & & & \\
\hline & 0,0000 & & & & & & \\
\hline \multirow[t]{2}{*}{ Goal } & 0,9089 & 0,9775 & 1,0000 & & & & \\
\hline & 0,0000 & 0,0000 & & & & & \\
\hline \multirow[t]{2}{*}{ Objective } & 0,8944 & 0,9595 & 0,9566 & 1,0000 & & & \\
\hline & 0,0000 & 0,0000 & 0,0000 & & & & \\
\hline \multirow[t]{2}{*}{ Corporates $\sim \mathrm{y}$} & 0,9450 & 0,9226 & 0,9319 & 0,9116 & 1,0000 & & \\
\hline & 0,0000 & 0,0000 & 0,0000 & 0,0000 & & & \\
\hline \multirow[t]{2}{*}{ Consistency } & 0,7696 & 0,6069 & 0,6149 & 0,6975 & 0,7001 & 1,0000 & \\
\hline & 0,0000 & 0,0000 & 0,0000 & 0,0000 & 0,0000 & & \\
\hline \multirow[t]{2}{*}{ Monitoring } & 0,9533 & 0,8266 & 0,8321 & 0,8036 & 0,8824 & 0,7454 & 1,0000 \\
\hline & 0,0000 & 0,0000 & 0,0000 & 0,0000 & 0,0000 & 0,0000 & \\
\hline \multirow[t]{2}{*}{ Businessu-ls } & 0,8824 & 0,7481 & 0,7766 & 0,7260 & 0,8123 & 0,6726 & 0,8950 \\
\hline & 0,0000 & 0,0000 & 0,0000 & 0,0000 & 0,0000 & 0,0000 & 0,0000 \\
\hline \multirow[t]{2}{*}{ Businessu-es } & 0,9585 & 0,8184 & 0,8238 & 0,7996 & 0,8904 & 0,7457 & 0,9804 \\
\hline & 0,0000 & 0,0000 & 0,0000 & 0,0000 & 0,0000 & 0,0000 & 0,0000 \\
\hline \multirow[t]{2}{*}{ Actionspla-t } & 0,9606 & 0,7731 & 0,8086 & 0,7739 & 0,8649 & 0,7427 & 0,9494 \\
\hline & 0,0000 & 0,0000 & 0,0000 & 0,0000 & 0,0000 & 0,0000 & 0,0000 \\
\hline \multirow[t]{2}{*}{ Actionplan-e } & 0,9513 & 0,7552 & 0,7906 & 0,7651 & 0,8472 & 0,7298 & 0,9315 \\
\hline & 0,0000 & 0,0000 & 0,0000 & 0,0000 & 0,0000 & 0,0000 & 0,0000 \\
\hline \multirow[t]{2}{*}{ HIV/AIDS } & 0,6721 & 0,4151 & 0,4841 & 0,4800 & 0,5551 & 0,4117 & 0,5574 \\
\hline & 0,0000 & 0,0000 & 0,0000 & 0,0000 & 0,0000 & 0,0000 & 0,0000 \\
\hline \multirow[t]{2}{*}{ BEE } & 0,6970 & 0,4745 & 0,5234 & 0,5166 & 0,5838 & 0,4747 & 0,5885 \\
\hline & 0,0000 & 0,0000 & 0,0000 & 0,0000 & 0,0000 & 0,0000 & 0,0000 \\
\hline
\end{tabular}


Table 5: Cronbach alpha analysis for internal consistency

\begin{tabular}{lccllll}
\hline Item & obs & sign & $\begin{array}{l}\text { item-test } \\
\text { correlation }\end{array}$ & $\begin{array}{l}\text { item-rest } \\
\text { correlation }\end{array}$ & $\begin{array}{l}\text { inter-item } \\
\text { correlation }\end{array}$ & alpha \\
Mission & 100 & + & 0,8853 & 0,8618 & 0,7387 & 0,9688 \\
Goal & 100 & + & 0,9085 & 0,8894 & 0,7343 & 0,9682 \\
Objective & 100 & + & 0,8961 & 0,8746 & 0,7366 & 0,9685 \\
Corporate $\sim$ y & 100 & + & 0,9450 & 0,9332 & 0,7273 & 0,9670 \\
Consistency & 100 & + & 0,7770 & 0,7346 & 0,7593 & 0,9720 \\
Monitoring & 100 & + & 0,9536 & 0,9436 & 0,7257 & 0,9668 \\
Businessu $\sim \mathrm{s}$ & 100 & + & 0,8823 & 0,8582 & 0,7393 & 0,9689 \\
Businessu $\sim \mathrm{es}$ & 100 & + & 0,9586 & 0,9496 & 0,7247 & 0,9666 \\
Actionplan $\sim \mathrm{t}$ & 100 & + & 0,9600 & 0,9514 & 0,7245 & 0,9666 \\
Actionplan $\sim \mathrm{e}$ & 100 & + & 0,9503 & 0,9397 & 0,7263 & 0,9669 \\
HIV/AIDS & 100 & + & 0,6677 & 0,6094 & 0,7802 & 0,9750 \\
BEE & 100 & + & 0,6947 & 0,6401 & 0,7750 & 0,9743 \\
\hline Test Scale & & & & 0,7410 & 0,9717 \\
\hline
\end{tabular}

The final analysis that was performed was a cluster analysis (Annexure A). The companies were clustered according to the top 61 and the bottom 39 companies based on the average disclosure on all of the twelve variables.

Among the top 61 companies, there were 6 companies with 100 per cent disclosure. There were 18 companies that had a score of over 90 per cent, 7 companies with greater than 80 per cent, and 12 companies with over 70 per cent disclosure. A total of 43 of the 61 top companies made more than 70 per cent disclosure.

From the bottom 31 companies, 11 companies made less than 10 per cent disclosure on the 12 variables. The remaining 20 companies made partial disclosure.

It is evident that many companies do not make maximum disclosure as this is not required by law. One would expect the extent of strategy disclosure to be much higher considering the sample selected were listed companies however only 6 per cent made maximum disclosure.

\section{Conclusion}

The research question was: to what extent do South African firms disclose their strategy in their Annual Report?

The main finding of the study is that South African Listed companies generally do disclose a lot of information about their corporate strategy. This is inconsistent with prior studies ( Santema \& Van de Rijt, 2001:107) which found that Dutch listed firms generally do not disclose a lot of information about their corporate strategy (Santema \& Van de Ritj, 2001:107).

The most common features of the present study are that companies in South Africa pay more attention in describing the strategy variables of mission, objective and goals. These 3 variables had the highest disclosure.

The sample of companies in this study was made up of hundred of the top two hundred listed companies. One would therefore expect the extent of strategy disclosure to be much higher as the stakeholders rely on the Annual Reports to make economic decisions. It can be seen that since strategy disclosure is voluntary and not required by law, there is a tendency to make sufficient disclosure to appease the stakeholders without reporting on any information that may cause the company to be placed in jeopardy. Companies are reluctant to disclose too much in these areas as the disclosure is voluntary; and if they make commitments in their Annual Reports they could be held to these.

The variables HIV/AIDS and BEE scores were the lowest scores in the present study, but cognisance must be given to the fact the South African economy is still in transition. However, the scores obtained from these variables are a 
good indicator that firms operating in South Africa consider the HIV/AIDS and BEE variables as part of their strategy disclosure to some extent. The companies that did disclose strategy on HIV/AIDS acknowledge the threat and impact of HIV/AIDS and there is some strategy in place to mitigate this threat.

Overall the scores of the variables indicate that South African companies generally do disclose a lot more information on their strategy. The differences in results between the Dutch study and the South African study can be attributed to many reasons. The main reason being that firstly, the Santema and van de Rijt study was conducted in 2001 and there has been much more emphasis on corporate governance since then. During this large time lag there have been many changes in corporate governance developments, amendments in company legislations and the general manner in which firms conduct their operations. Society is now demanding greater transparency and accountability from firms than ever before. In order for firms to remain globally competitive, they need to disclose more information on the non -financial information, as stakeholders are not interested only in the financial aspects of Annual Reports.

This study did not question the content of the strategy nor was the correctness of a particular strategy of a company tested. The purpose of this study was not to interrogate the particular strategy adopted but rather to test the disclosure of that strategy to the various stakeholders.

The main limitation of this study is that it evaluated strategy disclosure of one hundred companies for one year only. Future research could assess the same variables for the same companies over a longer period of time and compare the extent of disclosure. While this study focuses on the extent of strategy disclosure, future research could analyse the correlation between the extent of strategy disclosure and the profitability of the company. A further aspect of investigation could focus on whether more strategy disclosure could have a bearing on the rating of the company. It would also be interesting to assess whether the new King III would have any impact on the extent of strategy disclosure by companies with regard to their nonfinancial information in Annual Reports.

\section{References}

Al-Razeen, A. \& Karbhari, Y. 2004. 'Interaction between compulsory and voluntary disclosure in Saudi Arabian corporate annual reports', Managerial Auditing Journal, 19: 351-360.

Bowman, E. H. 1978. 'Strategy, annual reports, and alchemy', California Management Review, 20: 64-71.

Bukh, P.N., Nielsen, C., Gormsen, P. \& Mouritsen, J. 2005. 'Disclosure of information on intellectual capital in Danish IPO prospectuses', Accounting, Auditing \& Accountability Journal, 18(6): 713-732.
Du Bruyn, R. 2008. 'A proposed reporting framework for HIV/AIDS disclosure by listed South African Companies', Meditari Accountancy Research, 16(1): 59-78.

Ferreira, D. \& Rezende, M. 2007. 'Corporate strategy and information disclosure,' Rand Journal of Economics, 38(1): 164-184.

Financial Mail. 2005. Top 2005 companies: SA giants . [online]

URL:http://www.topcompanies.co.za/topcos2005/table/giant ab2 html. Accessed: 10/04/2007.

Flostrand, P. \& Strom, N. 2006. 'The valuation relevance of non-financial information', Management Research News, 29(9): 580-597.

IOD. 2009. Draft code of governance principles for South Africa 2009- King Committee on Governance. Johannesburg: Institute of Directors Southern Africa.

Kohut, G. \& Segars, A. 1992. 'The president's letter to stockholders: An examination of corporate communication strategy', Journal of business communication, 29 (1):7-21.

SAICA. 2009/2010. The Companies Act No 61 of 1973. Volume 1. Pretoria: Government Printer.

SAICA. 2009. International financial reporting standards. South African Institute of Chartered Accountants.

Santema, S., Hoekert, M., Van de Rijt, J. \& Van Oijen, A. 2005. 'Strategy disclosure in annual reports across Europe: A study on differences between five countries', European Business Review, 17(4): 352-366.

Santema, S. \& Van de Ritj, J. 2001. 'Strategy disclosure in Dutch annual reports', European Management Journal, 19(1): 101-108.

Vanstraelen, A., Zarzeski, M. \& Robb, S. 2003. 'Corporate nonfinancial disclosure practices and financial analyst forecast ability across three European countries', Journal of International Financial Management \& Accounting, 14, 249-278.

Yuthas, K., Rogers, R. \& Dillard, J. 2002. 'Communicative action and corporate annual reports', Journal of Business Ethics, 41(1): 141-157. 
Annexure A- Top 61 and bottom 39 companies based on strategy disclosure

(Due to confidentiality the company names have been omitted).

\begin{tabular}{|c|c|}
\hline $1 . \mid$ & C13 91.66666 Top 61। \\
\hline 2. & C26 54.16667 Top 61 \\
\hline 3. & C27 56.25 Top 61। \\
\hline 4. & C28 60.41667 Top 61। \\
\hline 5.1 & C44 56.25 Top 61। \\
\hline 6.1 & C45 56.25 Top 61। \\
\hline 7. & C46 56.25 Top 61 \\
\hline 8.1 & C47 60.41667 Top 61। \\
\hline 9.1 & C48 62.5 Top 61 \\
\hline 10. & C49 62.5 Top 61। \\
\hline $11 . \mid$ & C50 62.5 Top 61। \\
\hline 12. & C51 66.66666 Top 61। \\
\hline 13. & C52 66.66666 Top 61| \\
\hline 14. & C53 77.08334 Top 61| \\
\hline 15. & C54 58.33333 Top 61| \\
\hline $16 . \mid$ & C55 60.41667 Top 61। \\
\hline 17. & C56 66.66666 Top 61| \\
\hline 18. & C57 66.66666 Top 61| \\
\hline 19. & C58 68.75 Top 61। \\
\hline 20. & C59 68.75 Top 61। \\
\hline $21 . \mid$ & C60 70.83334 Top 61। \\
\hline 22. & C61 70.83334 Top 61 \\
\hline 23. & C62 70.83334 Top $61 \mid$ \\
\hline 24. & C63 70.83334 Top 61| \\
\hline 25. & C64 70.83334 Top 61| \\
\hline $26 . \mid$ & C65 72.91666 Top 61। \\
\hline 27. & C66 75 Top 61| \\
\hline 28. & C67 75 Top 61| \\
\hline 29. & C68 75 Top 61 \\
\hline 30. & C69 75 Top 61| \\
\hline $31 . \mid$ & C70 79.16666 Top 61। \\
\hline 32. & C71 81.25 Top 61। \\
\hline 33. & C72 81.25 Top 61 | \\
\hline 34. & C73 95.83334 Top 61। \\
\hline 35. & C74 83.33334 Top 61| \\
\hline 36. & C75 83.33334 Top 61। \\
\hline 37. & C76 87.5 Top 61 \\
\hline 38. & C77 87.5 Top 61 \\
\hline 39. & C78 91.66666 Top 61। \\
\hline 40. & C79 91.66666 Top $61 \mid$ \\
\hline 41. & C80 91.66666 Top 61। \\
\hline 42. & C81 91.66666 Top 61। \\
\hline 43. & C82 91.66666 Top $61 \mid$ \\
\hline 44. $\mid$ & C83 91.66666 Top 61। \\
\hline 45. & C84 93.75 Top 61। \\
\hline 46. & C85 93.75 Top 61। \\
\hline 47. & C86 95.83334 Top 61 \\
\hline 48. & C87 95.83334 Top 61 \\
\hline 49. & C88 95.83334 Top 61 \\
\hline
\end{tabular}

50. | C89 95.83334 Top 61 |

51.| C90 95.83334 Top 61|

52.| C91 95.83334 Top 61|

53. C92 95.83334 Top 61

54. $\quad$ C93 97.91666 Top 61|

55. | C94 100 Top 61|

56.| C95 100 Top 61 |

57. $\quad$ C96 100 Top 61|

58. $\quad$ C97 100 Top 61

59. $\quad$ C98 100 Top 61

60. C99 100 Top 61|

61.| C100 89.58334 Top 61|

62. $\quad \mathrm{C} 1 \quad 0$ Bottom $39 \mid$

63. C2 6.25 Bottom 39|

64. C3 6.25 Bottom 39|

65. C4 8.333333 Bottom 39|

66. C5 8.333333 Bottom 39

67. C6 8.333333 Bottom 39|

68. C7 8.333333 Bottom 39|

69. C8 8.333333 Bottom 39

70. C9 8.333333 Bottom $39 \mid$

71. C10 8.333333 Bottom 39|

72.| C11 8.333333 Bottom 39|

73. C12 12.5 Bottom 39|

74. C14 20.83333 Bottom 39|

75. C15 25 Bottom 39|

76. $\quad$ C16 25 Bottom $39 \mid$

77. $\quad$ C17 25 Bottom 39|

78. C18 31.25 Bottom 39|

79. $\quad$ C19 31.25 Bottom 39|

80. C20 31.25 Bottom 39|

81.| C21 31.25 Bottom 39|

82. C22 31.25 Bottom 39|

83. C23 33.33333 Bottom 39|

84. C24 33.33333 Bottom 39 |

85. $\quad$ C25 33.33333 Bottom 39|

86. C29 37.5 Bottom 39|

87. C30 37.5 Bottom 39|

88. C31 37.5 Bottom 39|

89. C32 39.58333 Bottom 39

90. C33 39.58333 Bottom 39|

91.| C34 41.66667 Bottom 39|

92. C35 41.66667 Bottom 39|

93. C36 45.83333 Bottom $39 \mid$

94. $\quad$ C37 45.83333 Bottom 39|

95. C38 45.83333 Bottom 39|

96. C39 45.83333 Bottom 39|

97. $\quad$ C40 45.83333 Bottom 39|

98. C41 45.83333 Bottom $39 \mid$

99. $\quad$ C42 45.83333 Bottom $39 \mid$

100.| C43 52.08333 Bottom $39 \mid$ 
